NBER WORKING PAPER SERIES

\title{
EXPLAINING PREFERENCES FOR CONTROL RIGHTS IN STRATEGIC ALLIANCES: A PROPERTY RIGHTS AND CAPABILITIES PERSPECTIVE APPROACH
}

\author{
Carolin Haeussler \\ Matthew J. Higgins \\ Working Paper 18364 \\ http://www.nber.org/papers/w18364
}

\author{
NATIONAL BUREAU OF ECONOMIC RESEARCH \\ 1050 Massachusetts Avenue \\ Cambridge, MA 02138 \\ September 2012
}

Haeussler acknowledges financial support from the German Research Foundation [SFB TR 15] and the Munich Center of Health Sciences. Higgins acknowledges financial support from The Imlay Professorship, the Greater Atlanta Regional Grants for the Study of Entrepreneurship and the Georgia Tech Center for International Business Education and Research (GT-CIBER) under a National center grant from the U.S. Department of Education. The views expressed herein are those of the authors and do not necessarily reflect the views of the National Bureau of Economic Research.

NBER working papers are circulated for discussion and comment purposes. They have not been peerreviewed or been subject to the review by the NBER Board of Directors that accompanies official NBER publications.

(C) 2012 by Carolin Haeussler and Matthew J. Higgins. All rights reserved. Short sections of text, not to exceed two paragraphs, may be quoted without explicit permission provided that full credit, including (c) notice, is given to the source. 
Explaining Preferences for Control Rights in Strategic Alliances: A Property Rights and Capabilities Perspective Approach

Carolin Haeussler and Matthew J. Higgins

NBER Working Paper No. 18364

September 2012

JEL No. D82,L14,M13,O32

\section{ABSTRACT}

Increases in alliance activity between research-intensive firms and incumbents is puzzling since it is challenging to contract upon highly uncertain R\&D activities. Our paper extends prior research by exploring the relationship between firm capabilities and preferences for control rights. This link is important because the allocation of control rights has been shown to influence alliance outcomes. Using data based on a survey of biotechnology firms, we find that both current and future capabilities provide strong explanatory power for understanding preferences for control rights. Our results allow us to integrate aspects of the capabilities perspective into the property rights framework.

Carolin Haeussler

Chair of Organisation

Technology Management and Entrepreneurship

University of Passau

Innstr. 27

D-94032 Passau

Germany

Carolin.Haeussler@Uni-Passau.De

Matthew J. Higgins

Georgia Institute of Technology

Scheller College of Business

800 West Peachtree Street

Atlanta, GA 30308

and NBER

matt.higgins@scheller.gatech.edu 


\section{INTRODUCTION}

Firms are often unable to sustain continuous high levels of productivity over long periods of time without accessing knowledge from beyond their boundaries; even leading firms require external knowledge to develop new innovations (Arora et al., 2001). This growing dependence upon external technology has caused the number of vertical transactions to dramatically increase. Correspondingly, there has been a vibrant increase in research focused on the contractual aspects of these inter-firm transactions since, as Parkhe argued, "the performance of a strategic alliance will be significantly related to the pattern of payoffs characterizing it" (1993: 799). Ultimately, this means finding an efficient and incentive compatible allocation of rights within these contractual agreements thereby inducing behavior that optimizes project returns. In other words, ex ante allocation of rights should be optimized in order to maximize ex post gains from trade. This suggests that the formation of preferences for rights plays an important role in this process. While little is currently known about how firms form these preferences, understanding them adds to our knowledge about property rights distribution within alliances which has demonstrated implications on alliance performance (Lerner et al., 2003) and, ultimately, firm performance (Shan et al., 1994; Rothaermel and Deeds, 2004).

In his assessment of assets Demsetz argues that ownership should follow the benefits of specialization in knowledge; they "should gravitate to the party who possesses the specialized knowledge necessary to do a good job of setting the general goal of the cooperative effort and monitoring the degree to which various owners of inputs accomplish their tasks" (1997: 34-35). These specific assets and knowledge and their ability to marginally impact a project are directly tied to a firm's underlying bundle of capabilities. This bundle should cause a firm to prefer specific rights thereby aligning preferences with capabilities. Since rights come with a cost and an obligation, firms without a specific capability should be willing to trade relevant rights to their partner if that partner has the capability.

Recent studies on control rights have focused on their allocation (e.g., Lerner and Merges, 1998; Ciccotello and Hornyak, 2000; Higgins, 2007; Elfenbein and Lerner, 2003, 2010), role in value appropria- 
tion (Adegbesan and Higgins, 2011), reducing opportunistic behavior (Kloyer, 2011; Kloyer and Scholderer, 2012) and impact on alliance outcomes (Lerner et al., 2003); however, researchers have had to make two limiting assumptions: (1) homogeneity of rights; and, (2) independence between rights. By homogeneously valuing rights information is not discernible about their relative importance. Moreover, having to assume independence between rights discounts the notion that they may be bundled (and negotiated) together. This may be of particular concern for studies that focus on specific rights (e.g., Lerner and Malmendier, 2010) since it is possible that these rights are not actually allocated or negotiated independently. These limitations are not unknown and exist because researchers have only been able to analyze ex post allocations of rights contained in executed contracts.

Using data from a survey of international biotechnology firms we study the relationship between firm capabilities and their preferences for control rights and in doing so we are able to overcome the aforementioned limitations and make several contributions to the literature. First, we present empirical evidence on the existence of preferences for rights and the extent of heterogeneity that exists between them. Using factor analysis we identify bundles of rights that are interdependent upon each other, which we categorize as either "upstream" or "downstream". By having this more complete understanding of preferences we are better able to analyze what drives their formation. We argue that capabilities and control should be aligned whereby preferences for control rights flow from a firm's specific capability set. Consistent with this notion, we find that current firm capabilities predict preferences for rights. This suggests that by aligning strategy and organizational activities (Gawer and Henderson, 2007) firms can optimize their preferences for specific rights which, in turn, should influence eventual ex post allocation and subsequent alliance performance.

Moving beyond the static view of current capabilities we also surveyed firms about their future plans to expand downstream in order to acquire commercialization capabilities. For firms that acknowledged an expansion plan we find that they prefer bundles of rights that are not only consistent with their current capabilities but also rights consistent with their expansion plans. This suggests that firms appear to form preferences for rights that match future capabilities before they acquire those assets. Obtaining such 
rights provides firms with an incentive to build up these capabilities; a view consistent with the property rights and closely related incentive systems literatures (Gibbons, 2005). Moreover, firms may enter into alliances in order to learn and profit from partner experience when building these capabilities. Despite this desire to learn and acquire capabilities it may be the case that such capabilities end up being duplicated thereby increasing costs. It may also be the case that the firm has an undetermined downstream expansion strategy or reflects some type of potential underinvestment. In either of these two cases such a preference bundling is inconsistent with the literature (e.g., Demsetz, 1988; Hart and Moore, 1990) and is inefficient since rights are not costless to obtain and come with an obligation.

Prior literature stresses the importance of alliance capabilities and documents a positive relationship with firm-level patenting (Shan et al., 1994), positive stock market responses (Anand and Khanna, 2000; Kale et al., 2002) as well as with alliance performance (Kale et al., 2002; Hoang and Rothaermel, 2005; Schilke and Goerzen, 2010). We add to this literature by demonstrating that the strength of alliance capabilities are positively related to preferences for upstream control rights. While previous studies have focused on the direct effect of alliance capabilities on alliance performance, our results imply that these capabilities impact the underlying contractual structure of an alliance, which is long before performance can be assessed. This alignment with rights provides an additional explanation for the link between capabilities and performance.

Finally, our study demonstrates that the capabilities perspective offers important insights that allow us to make extensions to the property rights framework. The Grossman, Hart and Moore (GHM) framework suggests that control rights should be allocated to the partner who can have the highest marginal impact on project success. ${ }^{1}$ The literature, however, is silent about how firms differ in terms of "marginal impact". One possible explanation for these differences lies in the heterogeneity of firm capabilities and, indeed, we find that this heterogeneity leads firms to prefer different bundles of control rights. By aligning preferences for rights and capabilities, firms with the knowledge or ability will be better able to direct specific alliance activities (Demsetz, 1988) thereby contributing the marginal impact suggested

\footnotetext{
${ }^{1}$ Grossman and Hart (1986), Hart and Moore (1988), Hart (1995) and Hart and Moore (1999).
} 
by the GHM framework. In other words, rights follow the benefits of specialization in knowledge (Kogut and Zander, 1993).

\section{RELATED LITERATURE}

\subsection{Current capabilities and preferences for control rights}

Central to the capabilities perspective is the idea that firms differ in their capabilities or resource positions, and that such heterogeneity explains market position (Gawer and Henderson, 2007) and is a source of performance difference across firms (Barney, 1991; Peteraf, 1993; Henderson and Cockburn, 1994). These capabilities, which can give rise to competitive advantage, are not merely simple assets but rather compound asset structures which are built over time and can be path dependent (Teece et al., 1992; Deeds et al., 1999). Two assumptions underpin the capabilities perspective: (1) firms are heterogeneous with respect to their capabilities or resource profiles; and, (2) these capabilities or resources are not perfectly mobile across firms (Barney, 1991).

The emphasis on firm heterogeneity resulting from differences in capabilities is a particularly important notion in explaining vertical specialization and cooperation. The entirety of the value chain for an industry is composed of various activities (e.g., research, development, manufacturing, sales and marketing) which often demand very specific capabilities. In some instances certain steps of the value chain are carried out by firms with the specialized capabilities. For example, in the pharmaceutical industry, contract research organizations have emerged and focus on clearly defined research tasks.

In general, activities which require the same or closely related capabilities are deemed "similar". These similar activities are seldom complementary, since complementary activities typically occupy different stages of the value chain. Richardson (1972: 888) argues that firms “...would find it expedient, for the most part, to concentrate on similar activities", since incorporating "dissimilar" activities may lead to diseconomies of scope and/or increased information or transaction costs.

Scholars have widely documented that firms are increasingly specializing along the value chain with research intensive firms often selling or licensing their intellectual property to incumbents in the 
market for technology (Bresnahan and Gambardella, 1998; Arora and Ceccagnoli, 2006) or the market for ideas (Gans and Stern, 2000; Gans et al., 2002; Haeussler, 2011). Pharmaceutical firms often hold important downstream capabilities or co-specialized assets that their research intensive, biotechnology firm partners often lack, including manufacturing, distribution, marketing and sales (Chan et al., 2007; Haeussler et al., 2012). Likewise, biotechnology firms have been a source of new, innovative upstream research for incumbent firms (Higgins and Rodriguez, 2006). Moreover, for many biotechnology firms, alliances are important sources of financing and revenues as well as important means to bring a product onto the market.

If we accept the assumption that the capabilities perspective implies that firms possess different bundles of capabilities, then this has direct implications for contracting. A firm's current capability set should be taken into account when contracts are negotiated. Firms possessing capabilities in a specific area not only provide them with unique expertise but may also make them particularly capable of coping with problems associated with that area. Indeed, capabilities derived from specific firm knowledge have been identified as a source of competitive advantage (Kogut and Zander, 1996). Demsetz (1988: 157-158) suggests that partners who lack capabilities or knowledge in one relevant area "... must have their activities directed by those who possess (more of) the knowledge". Put differently, the right to decide should rest upon how effectively a firm is able to decide and this depends on their capabilities. As such, capabilities and control should thus be aligned whereby preferences for control rights flows from a partner's specific capability set. In this instance, firms also minimize potential transaction costs because they are not trying to negotiate or craft terms for which they have no expertise or limited contract design capability (Argyres and Mayer, 2007).

Unlike previous studies which emphasize that firms strive for more control rights in the sense of "more is the better" (e.g., Lerner and Merges, 1998), we argue that the current capabilities set of a firm directly influences their preferences for control rights. Retaining more rights might not always be beneficial: firms can be better off if they trade away control rights to a partner whose resources or capabilities set makes them better positioned to decide or direct alliance activities (e.g., a pharmaceutical partner might be 
better equipped to litigate or direct patent infringement suits than a research intensive firm). This view suggests that firms act in a manner whereby they form preferences for control rights that match their capabilities but that they are also willing to trade away rights that align with the capabilities of their partners. In sum, more may not always be better if the rights are not aligned with firm capabilities.

We take the view that an obligation comes with owning a specific control right. This obligation, which is often legally binding, requires a firm to make decisions in the best interest of the partnership. If a firm has limited knowledge or capabilities to arrive at the best solution, then it is possible that only a suboptimal level of success can be achieved. Given that in high-tech industries many incumbent firms have come to rely extensively on research intensive firms (Ceccagnoli et al., 2010) for new research inputs, it is critical that these firms attempt to construct contracts that will induce optimal performance in hopes of achieving a more favorable outcome.

This reliance on external technologies in the biopharmaceutical industry tends to be between large incumbent, pharmaceutical firms and smaller, research-intensive, biotechnology firms. As such, the majority of the relationships between these firms tend to be vertical in nature. Following our notion that firms will prefer rights that match or align with their capabilities, we propose that firms with strengths in upstream capabilities will have a greater preference for control rights related to upstream activities whereas firms with strengths in downstream commercialization capabilities will have a greater preference for rights related to these downstream activities.

\subsection{Future commercialization capabilities and preferences for control rights}

We recognize, however, that firms are not static entities but are constantly developing and changing. This also means that the capability bundle of a firm will continue to develop both inside and outside of partnerships. Scholars have emphasized the ability to change and quickly develop capabilities for sustained competitive advantage. This ability to continuously renew capabilities has come to be known as “dynamic capabilities" (Teece et al., 1997; Eisenhardt and Martin, 2000; Zollo and Winter 2002), “dynamic core competencies" (Danneels, 2002) or "second-order competences" (Danneels, 2008). 
The existing literature on property rights has focused on the "static management of innovation" (Aghion and Tirole, 1994: 1206). However the dynamic aspects of research activities are particularly important with regard to vertical alliances. One of the most widely cited motives for collaboration is the acquisition of capabilities from partner firms (Hamel et al., 1989; Shan, 1990; Hamel, 1991; Powell and Brantley, 1992; Mody, 1993; Khanna, 1996; Mowery et al., 1996). In this instance, firms enter alliances in order to learn from a partner. This is consistent with Helfat et al.'s (2007) notion of dynamic capabilities as "the capacity of an organization to purposefully extend, create or modify its resource base." Recent evidence suggests that this is the case with acquiring downstream commercialization capabilities (Hamel, 1991; Khanna et al., 1998; Rothaermel and Deeds, 2004; Hsu and Wakeman, 2012). For example, Hsu and Wakeman (2012) argues that biotechnology firms enter alliances with pharmaceutical partners in order to observe commercialization practices thereby acquiring the necessary skills to commercialize future products alone. As such, we expect biotechnology firms that plan on expanding downstream will first want to learn from existing alliance partners.

When firms enter into alliances in order to gain access to other firms' capabilities, the alliance learning effect may be greater when they also acquire the rights to decide on activities associated with the (aimed) activity. For example, research on joint ventures suggests that parent learning is greater when managers of the parent firm are involved in decisions and spend time at the joint venture (Inkpen and Crossan, 1995). Therefore, we assume that biotechnology firms that do not have current downstream commercialization capabilities but have a desire to expand downstream will have a higher preference for control rights related to commercialization activities versus firms that do not have the intention to expand

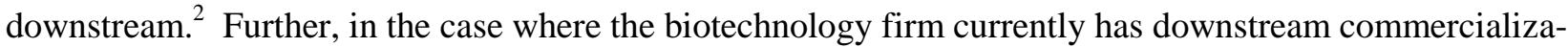
tion capabilities, we would also expect them to prefer the relevant related control rights.

The question arises as to why biotechnology firms that specialize in upstream R\&D activities would want to acquire downstream commercialization capabilities. Hsu and Wakeman (2012) provides

\footnotetext{
2 A parallel proposition would be that firms with an upstream expansion strategy have a stronger preference for upstream control rights. However, in our setting, an upstream expansion is unlikely as many of firms are spin-offs from a university or public research lab and already perform basic science.
} 
two possible reasons stemming from the economics of organization literature. First, they may want to mitigate possible small numbers bargaining problems. Pisano (1991) notes that biotechnology firms that are highly specialized or focused in one therapeutic area may become dependent upon on a limited number of commercialization partners. In such a situation, the biotechnology firm risks potentially exposing itself to 'hold-up' problems during the negotiation process. Second, the biotechnology firm may want to strengthen their appropriability position over the profit stream from its innovation. Teece (1986) argues that acquiring co-specialized capabilities, in this case downstream commercialization capabilities, increases a firm's appropriability over an innovation. ${ }^{3}$ Rival firms would need to create or imitate the technology and build similar commercialization assets in order to compete (Hsu and Wakeman, 2012).

Notwithstanding this desire to acquire capabilities and learn, it is possible that certain capabilities end up being duplicated leading to an increase in costs. In fact, Mowery et al. (1998) provide evidence that this type of technological overlap increases in cooperative arrangements. As such, firms potentially face a dilemma: partners may have competitive, as well as collaborative aims vis-à-vis each other where they try to acquire one another's capabilities. This may well result in a "competition for competence" that ultimately destabilizes the relationship (Hamel, 1991). In the biopharmaceutical industry, for example, Rothaermel and Deeds (2004) observe that when biotechnology ventures grow they tend to withdraw from their upstream focus in order to develop and commercialize promising projects through downstream expansion which ultimately leads them to compete with former alliance partners.

\subsection{Alliance capabilities and preferences for control rights}

Besides capabilities associated with specific activities along the value chain, the alliance capability of a firm may also impact preferences for control rights. Alliance capability is the ability to effectively capture, share, monitor and distribute alliance management know-how and can take the form of dedicated

\footnotetext{
${ }^{3}$ It is theoretically possible that a firm that does not currently have downstream commercialization capabilities and has $\underline{n o}$ intent or plans to develop them could still prefer the relevant downstream rights in order to mimic those firms that intend or plan to downstream integrate. If it is the case that firms make the move downstream and develop commercialization capabilities in order to protect against potential hold-up problems, these other firms may be trying to mimic those firms without making the requisite downstream investment. While a theoretic possibility, we do not see this in our data. There is a significant difference in the preferences for downstream rights between those firms that intend to downstream integrate and those that do not (Wilcoxon rank-sum test of differences in two samples: $\mathrm{p}<0.001)$.
} 
alliance personnel, databases, tools, metrics and alliance experience (Kale et al., 2002). Prior research documents a positive relationship between alliance capability and increases in firm-level patenting (Shan et al., 1994), positive stock market responses (Anand and Khanna, 2000; Kale et al., 2002) as well as on alliance performance (Kale et al., 2002; Hoang and Rothaermel, 2005).

Notwithstanding these findings, different types of alliances and different tasks within these partnerships may make alliance capability more or less important. For example, existing work points to the strength of alliance capabilities in being particularly important for upstream (R\&D related) activity. In their study of the automotive industry, Clark and Fujimoto (1990) find that central coordination of development decreased the time and cost involved in developing new product designs. Similarly, studying the pharmaceutical industry, Henderson and Cockburn (1994) suggest that higher-order organizing mechanisms are particularly useful to coordinate R\&D. They argue that having an individual or team responsible for coordinating internal and external R\&D increases productivity. Further, Hoang and Rothaermel (2005) find that the alliance experience of biotechnology firms increases joint R\&D project success. However, alliance experience of their pharmaceutical partner did not provide the same effect, which they argue may be the result of being "further down the learning curve".

March (1991) and Levinthal and March (1993) present an exploration-exploitation framework to understand the needs of firms at different stages along the value chain. Applying this framework to analyze alliances between biotechnology and pharmaceutical firms, exploration is related to upstream research activities aimed at discovering something new (Koza and Lewin, 1998). These activities are most often performed by the biotechnology firm and are highly uncertain with most biotechnology drug candidates not making it into clinical trials (Giovannetti and Morrison, 2000). In this highly uncertain context, greater alliance capabilities are clearly beneficial to the firm. For example, they may allow the firm to respond more quickly to underlying changes in a specific project. On the other hand, committing greater alliance capabilities or resources to a project comes with added risks. One way to mitigate some of this potential risk is through the bundle of upstream control rights. Firms not only aim to own underlying intellectual property (IP) but they can also avoid potential appropriation via reversion rights (Lerner and 
Malmendier, 2010). As such, we expect biotechnology firms that commit a larger percentage of their alliance capabilities to a project to be more likely to prefer upstream rights.

In contrast, this means exploitation activities are related to downstream activities including: laterstage development, regulatory approval, manufacturing, and marketing. Downstream activities are typically more regulated and have lower uncertainty than upstream activities. ${ }^{4}$ Again, focusing on the biopharmaceutical industry, pharmaceutical firms have developed the legal and regulatory competence, manufacturing, distribution and marketing capabilities (Cullen and Dibner, 1993) needed to take products to market (Rothaermel and Deeds, 2004; Chan et al., 2007). Many of these activities will end up being controlled by the pharmaceutical partner. As such, alliance capabilities of the research-intensive (biotechnology) partner should become less important in this context.

To summarize current theory, in particular the GHM framework proposes that the marginal ability to affect outcome should determine the allocation of control rights. However, the literature is silent on the nature of this marginal ability. We propose that firm capabilities might be strongly related to marginal ability and in doing so we extend the GHM framework by adding insights from the capabilities literature. More specifically, we propose the set of current as well as future planned capabilities should be positively related to a firm's preferences for control rights. In case of future planned capabilities, firms prefer rights before they build up these capabilities; a view that is consistent with the notion of preventing underinvestment in the property rights and incentive systems literatures (Gibbons, 2005).

\section{DATA AND METHODS}

\subsection{Research setting}

Given our research focus on vertical R\&D relationships between large incumbent firms and smaller, research intensive firms we choose the international biopharmaceutical industry as our research setting.

\footnotetext{
${ }^{4}$ In the pharmaceutical industry, virtually all aspects of downstream development are regulated by the FDA. Strict regulatory rules govern clinical phase testing as well as the manufacturing and marketing process. In contrast, upstream activities, primarily those before clinical testing, are fairly unregulated. Furthermore, prior work has documented a decrease in uncertainty in developing a new drug (i.e., an increase in transition probability) as a potential candidate moves through the various stages of clinical development; the risk of failure is greatest during upstream activities (e.g., Krieger and Ruback, 2001)
} 
This industry is rife with young technology firms that often have promising ideas but lack the financial resources and complementary assets in order to move those ideas to market. On the flip side, it is an industry where incumbent (pharmaceutical) firm pipelines are shrinking (Higgins and Rodriguez, 2006) and they are becoming ever more dependent upon external research (Ceccagnoli et al., 2010) in order to keep their downstream co-specialized assets fully deployed (Chan et al., 2007). This supply of new promising technologies coupled with an increased demand for them have created a robust market for technology. For example, Deloitte ReCap reports an increase of over $100 \%$ in the number of biopharmaceutical researchbased alliances between 1996 (1,023 deals) and $2007(2,348) .{ }^{5}$ In addition to the prevalence of deals, the industry faces long and expensive development cycles coupled with low probabilities of success. This makes the importance of contracting all the more critical, especially given the potential payoffs, which can exceed well into the billions of dollars per year for a "blockbuster" product.

These external transactions, it is important to note, are, at least, two-party deals. We focus on the perspective of the small, research-intensive, biotechnology firm. Lerner et al. (2003) demonstrates that right allocations consistent with theory (e.g., Aghion and Tirole, 1994) have performance implications with respect to alliance outcome. One of the goals of our research is to provide intuition on how managers might improve alliance outcomes. As such we need to understand how suppliers of new technology form preferences for specific rights.

\subsection{International biotechnology survey}

In contrast to previous studies that analyze ex post allocation of rights in alliance contracts $(e . g$, Higgins 2007; Lerner and Merges 1998; Lerner et al., 2003; Elfenbein and Lerner, 2010; Adegbesan and Higgins, 2011), our empirical strategy sets out to measure a firm's ex ante preference for control rights. ${ }^{6}$ This kind of data is unavailable in public databases but is nonetheless desirable. By focusing on prefer-

\footnotetext{
${ }^{5}$ Authors calculation based on information accessed from the Deloitte Recap database, www.recap.com. We thank Mark Edwards and Deloitte Recap for access to their data.

${ }^{6}$ The focus on ex post allocations of rights in the literature has been as a result of data availability. Much of the work in this field has focused around data made available by Deloitte Recap. Other researchers, for example, Ciccotello and Hornyak (2000) have constructed their own proprietary datasets using data from the United States Air Force.
} 
ences we get a more complete understanding of how firms view particular rights without the possible distortion caused by the negotiating process or appropriation issues due to bargaining position. We therefore designed and administered an international survey in 2009.

We approached biotechnology firms located in North America (USA and Canada) and eleven European countries (Austria, Belgium, Denmark, Finland, France, Germany, Italy, Netherlands, Sweden, Switzerland, United Kingdom). Firms that were not founded in one of the thirteen countries, were subsidiaries of foreign firms, were younger than one year old or ones for which we could not obtain adequate contract information were excluded. Our sample was identified through several industry databases (e.g., Bioscan, Biocom, Dechema, as well as regional databases like Erbi). Our working sample started with 463 North American (15 Canadian and 448 US) and 1,758 European firms. Each firm received a personalized email addressed to the head of management or head of business development (if existed) requesting that it be directed to the person responsible for entering and negotiating alliances, inviting them to participate in the on-line survey. Overall, 365 managers filled out the survey resulting in an average response rate of $16 \% .^{7}$

We tested for potential non-response bias by comparing the answers to questions from the first wave of respondents with the last wave of respondents (Armstrong and Overton, 1977). We perform a conservative non-response analysis by testing whether the answers to our dependent variables concerning the preferences for rights and variable controlling for the age of firms differ significantly between the first $10 \%$ and last $10 \%$ of respondents. Our variable distinguishing between these two sets of respondents was not significant in either specification; non-response bias does not appear to be an issue.

\footnotetext{
${ }^{7}$ Firms were subsequently contacted via phone and by follow-up email. They were also given the opportunity to complete a hard copy of the survey, which was mailed to them, or to complete the survey over the phone. The response rate in our survey is comparable to other online surveys in this industry. We have a particularly high response rate for Germany (25\%) which is in line with previous survey studies documenting a higher willingness to respond to surveys in Germany compared to other EU countries (e.g., PatVal-EU Survey 2005). We specifically test country differences; the only right that demonstrated any significant country difference (stronger for North America) was Ownership of patents.
} 
Because all data are self-reported and collected through the same questionnaire during the same period of time, common method variance might also be a concern (Podsakoff and Organ, 1986). In order to avoid common method bias we placed the questions in a manner that did not reveal the intention of the analysis. In addition, we conducted a Harman test for the presence of common method effect (Podsakoff and Organ, 1986). All variables were entered into an explanatory factor analysis, using unrotated principal component factor analysis, to determine the number of factors that are necessary to account for the variance in the variables. If a substantial amount of common method variance is present, either (a) a single factor does emerge or (b) one general factor will account for a majority of the covariance among the variables. The unrotated principal component analysis reveals that eight distinct factors with eigenvalues greater than 1.0 can be extracted. The (first) largest factor (Eigenvalue 1.95) accounts for $11 \%$ of the total variance. Thus, no single factor or general factor is apparent thereby suggesting that common method variance, which might inflate or deflate observed relationships between constructs, is also not a concern. ${ }^{8}$

Another possible concern could be that respondents expressed a personal opinion rather than the view which is held by the firm. In order to avoid such a bias, we explicitly directed the survey to the head of management or head of business development as described above. In addition, questions were placed in a manner such that respondents first had to answer firm specific questions before they were asked about their firm's preferences for control rights. From our pretests and conversations with several firms we gained confidence that respondents were answering on behalf of their firm.

Since the purpose of this study is to analyze the ex ante preferences for control rights, we use a subset of our survey data for which biotechnology firms entered into at least one alliance with a pharmaceutical firm. We know from prior literature that firms cede value (Nicholson et al., 2005) and control rights (Higgins, 2007) when engaging in a first alliance. More importantly, firms that have entered at least one alliance have had to contemplate preferences for rights in the context of an alliance agreement. By surveying firms that have never engaged in an alliance with a pharmaceutical firm the validity of the re-

8 We used all variables present in Table 3, Model 4. 
sponses might be suspect given that they have not been involved in the process of constructing and negotiating an agreement. The implication of this assumption and the relationship between alliance experience and preferences is discussed more fully in Section 4.3.2. With this focus our sample now includes 157 fully filled out questionnaires for which we had all necessary variables needed to conduct our analysis. (Table 1 approximately here)

\subsection{Variables and factor analysis}

\subsubsection{Dependent variables}

In our survey we asked our respondents about their preference for eight control rights that were deemed important by our pre-test interviews and which are also consistent with those considered in other studies (e.g., Lerner et al., 2003; Higgins, 2007; Adegbesan and Higgins, 2011). ${ }^{9}$ Columns 1-4 in Table 1 define each of these rights and presents their mean level of importance along with their standard deviation for biotechnology firms entering alliances with pharmaceutical partners on a five-point Likert scale ranging from "not important" (1) to "extremely important" (5). A score of three (3) indicates that the biotechnology firm ranked the right to be "important". Rights with values of less than three can thus be viewed as less important while those rights with a score of greater than three should be viewed as more important.

We learn from observing the data in Table 1 that heterogeneity exists in how biotechnology firms view the importance of control rights. While recognized in prior literature, this is the first time, we believe, that this heterogeneity has been demonstrated. An analysis of the means is interesting, for example, the Ownership of patents was deemed to have the highest importance (3.9) followed by Product reversion rights upon termination (3.6). ${ }^{10}$ Not surprisingly, these rights provide strong protections over research

${ }^{9}$ Specifically, we asked: "We are interested in your preferences for specific payment terms and contractual rights before engaging in an alliance with a pharmaceutical firm. When thinking about the following sets of contractual provisions, please rank their importance."

${ }_{10}$ Several researchers emphasize the close relationship between equity ownership and control rights (see Pisano, 1989; Allen and Phillips, 2000). However, Grossman and Hart (1986) and Aghion and Tirole (1994) point out that residual income rights alone do not solve the incentive problem that results from incomplete contracting issues. Control rights on how assets are used must be considered. In this paper, the ownership of patents is treated as a control right. The right does not only allow capitalizing on the patented technology but includes the right to make decisions on usage. 
projects and intellectual property, which are the primary assets biotechnology firms bring to these partnerships. Surprisingly, Marketing rights to the product/technology are ranked third in importance (3.4). While many of the respondent firms lack the necessary capabilities and resources in order to market products, this might suggest these firms, in the longer term, have a desire to expand downstream and market their innovations.

\subsubsection{Factor analysis and the bundling of rights}

As a result of heterogeneity across preferences for rights, can we detect any interrelationship or interdependence between these rights? Given our theoretical interest in the dichotomy between upstream and downstream activities it is important for us to understand the possible relationship between our focal rights. In order to do this we use factor analysis. Factor analysis uses principal component analysis and Varimax rotation (Lattin et al., 2003). The number of factors extracted was determined by the Kaiser criterion (Eigenvalue > 1) and is consistent with our theoretical framework. Our two factors or bundles of control rights are identified in Table 1, Column 5 along with their factor loadings.

We classify the first bundle of four rights as "upstream rights" since they are related to the upstream or research activities of firms (Ownership of patents, Obligation to litigate patent infringement, Right to sublicense and Product reversion rights upon termination). These rights increase a biotechnology firm's flexibility (and outside options) making them less dependent on a specific partner while at the same time protecting their primary asset - their research output. For example, Ownership of patents not only secures formal property rights to a firm's research efforts and is a mechanism to generate revenues through licensing but also allows building upon previous patents in subsequent research efforts. Similarly, the Right to sublicense increases a biotechnology firm's ability to generate revenue from others thereby decreasing dependence on one partner. Product reversion rights upon termination protect a firm from possible hold-up or shelving and the Obligation to litigate patent infringement ensures protection and en- 
forcement of intellectual property rights should infringement occur. ${ }^{11}$ The dynamic capabilities literature highlights a firm's capacity to renew capabilities and shift resources in order to adapt to changes in the environment (Teece et al., 1997). Indisputably, this bundle of rights does in fact increase a firm's capability to adapt and even capitalize on a rapidly changing environment and, in addition, decrease dependence on any one specific alliance partner.

The second set of three rights is bundled together and relates to downstream activities: Management of clinical trials, Control of initial manufacturing, and Marketing rights to the product or technology. At first glance, it does not seem obvious why this pattern or bundle should flow out of biotechnology firm preferences; this type of preference bundle might be more easily related to a pharmaceutical firm. That said, it is important to note that the majority of our firms are involved in developing therapeutics/vaccines $71 \%, 43 \%$ are developing platform technologies and $22 \%$ are involved in diagnostics. ${ }^{12}$ On average, our firms already have at least one product on the market. As a result, given our prior discussion in Section 2.2, the breadth of sectors, current activities covered (and future expansion) in these downstream areas, the preference bundling seems appropriate.

Even though the Right to publish was identified in our pre-test interviews as being important, our factor analysis also reveals that it is neither a part of the upstream or downstream factors. One possible explanation for this exclusion from the literature suggests that for firms, publications provide a means of signaling the possession of tacit knowledge and building the technical reputation that is necessary for exchanging information particularly with academic scientists (Henderson and Cockburn, 1994). If this is the case then it seems reasonable that we do not see it in either of the factors.

Finally, a potential methodological issue arises when utilizing principal component analysis. Is assumes continuous, normally distributed variables while our measure for preferences for rights are based on

11 Knowles and Higgins (2011) discuss the tensions that exist between partners over some of these rights. For example, while a biotechnology firm may prefer to own the underlying IP, maintain the obligation to litigate patents and/or control IP strategy, these are terms that in-house legal counsel at pharmaceutical firms like to control in order to ensure their downstream investments are secure. Moreover, many biotechnology firms often do not have the financial resources to hire top legal counsel to draft patents or engage in protracted legal disputes, should they occur.

${ }^{12}$ These figures add to more than $100 \%$ because some firms cover more than one area. 
Likert scales. As such, we follow the rule of thumb that suggests that scales with four or more points, in fact, approximate the properties of interval scales (Hagedoorn and Hesen, 2009).

\subsubsection{Independent variables}

Our independent variables that capture information about a biotechnology firm's current and future capabilities are summarized along with bivariate correlations in Table 2 . This dual approach comes from prior work (Das and Teng, 2000) that notes that in order to adequately address the drivers or motivations for an alliance, research should not just focus on the capabilities that a firm does not own but should also consider a firm's current set of capabilities. (Table 2 approximately here)

Current $R \& D$ capabilities. We measure a biotechnology firm's current R\&D capabilities and define a dummy variable, Upstream capabilities, which is equal to 1 if a respondent assesses that the firm strongly covers basic research activities internally, 0 otherwise. In science-based industries, firms' upstream activities typically require interacting with universities and public research institutions that conduct basic research. A firm's basic research activities are often a signal for research capacity (Henderson and Cockburn 1998). In our sample $70 \%$ of firms strongly cover basic research.

Downstream capabilities. We measure the extent to which firms are involved in downstream commercialization activities and define a dummy variable, Downstream capabilities, which is equal to 1 if a firm strongly covers manufacturing, sales and marketing, 0 otherwise. A dummy variable is used because we are simply interested in distinguishing between those firms with a significance downstream presence versus those that do not. Only $20 \%$ of the firms in our sample are strongly covering these activities. Biotechnology firms are known to enter alliances with pharmaceutical firms in order to access the downstream capabilities needed to transform promising research into marketable products (Rothaermel and Deeds, 2004). These capabilities are often costly to fully develop and maintain and alliances help the firm avoid making investments that may not pay off or for which they cannot keep fully deployed. 
Downstream expansion. We proxy the Downstream expansion plans of a firm with a standardized index assessed along two dimensions: (i) the extent to which the motivation to enter the alliance was for developing internal marketing/distribution skills; and, (ii) the extent to which the motivation to enter the alliance was to learn from the partner's experience in marketing/distribution. ${ }^{13}$ This desire to learn and develop is consistent with recent literature (Hsu and Wakeman, 2012). These two motivations are measured on a five point Likert scale ranging from not important (1) to extremely important (5). Firms which rank these items as being highly important are more likely to follow a downstream expansion strategy.

Alliance capability. Alliance capability has been measured several ways in the literature, for example, by the percentage of the management team with a Ph.D. or M.D. (Deeds et al., 1999), by the firms alliance experience (Hoang and Rothaermel, 2005), or whether the firm had a dedicated individual or team responsible for alliance management (Kale et al., 2002). We define our primary measure of Alliance capability as a dummy that equals 1 if a firm commits more than $25 \%$ of their total research personnel to alliance projects. This measure has the advantage that it is independent of firm size and abstracts from the intensity of alliances. In our sample, $64 \%$ of firms devote at least $25 \%$ of their research personnel to alliance projects. Following Kale et al. (2002) we also asked firms to identify whether they had a dedicated individual or team that was responsible for the management of alliances. However, this second measure was not significant in any of our specifications. It could be the case that the difference in results with Kale et al. (2002) are the result of our focus on the smaller, research intensive partner versus the incumbent (pharmaceutical) firm.

\subsubsection{Control variables}

Alliances to acquire capital. Aghion and Tirole (1994) show that capital constraints can prevent parties from allocating control rights efficiently. In line with these theoretical observations, extant empirical work (e.g., Lerner and Merges, 1998; Lerner et al., 2003) find that external capital constraints lead to more rights being assigned to the financing partner. Unlike these studies, our focus is on preferences and

\footnotetext{
13 With an inter-item correlation that equals 0.42 .
} 
we include the extent to which receiving money from alliance partner motivates alliance activity. It may be the case that firms already take into account resource constraints when entering into negotiations. As such, we define a dummy, Alliances to acquire capital, which equals 1 if the biotechnology firm considers receiving money as a very important motive for entering an alliance with a pharmaceutical firm, 0 otherwise. Descriptive statistics reveal that capital acquisition is indeed important for firms; almost $80 \%$ of firms consider money to be a very important motive for partnering.

Needs access to IP. We consider a second motivation for entering an alliance, in this case, to access IP. We define a dummy variable that equals 1 if the respondent agrees that access to IP is either a very or extremely important motivation for entering an alliance with a pharmaceutical firm, 0 otherwise. Only $30 \%$ of our respondents indicated that this was a very or extremely important motivation for entering an alliance. It does suggest, however, that these firms aim to fill their development pipeline with externally acquired technology.

Early stage firm. We consider a firm to be early stage if it has products or technologies under development in the pre-clinical or pre-prototype stage but not in the later stages of the value chain (including clinical trial or prototype development and beyond). Early stage firm is a dummy that equals 1 if this criteria was met, 0 otherwise. We assume that earlier stage firms are more resource constrained relative to later stage firms. Twenty percent of the firms in our sample fall into this category. We note that since we are including diagnostic and platform companies and not just therapeutics, we have broader product information than might be contained in commercial databases. ${ }^{14}$

Firm age. We control for the age of the firm because older firms are likely to have a larger resource and capabilities stock (Rothaermel and Deeds, 2004). Moreover, since many of our sample firms are private, age may also serve as a proxy for firm size. We define Firm age as the years since firm's founding date and, on average, our firms are eleven years old.

\footnotetext{
${ }^{14}$ For example, the Pharmaprojects database could be used to identify therapeutics at various stages but no information would be available for our platform or diagnostic firms.
} 
Alliance experience. The experience garnered from entering more alliances may shape preferences for rights. As a result we control for the number of alliances each of our firms have entered. We define Alliance experience as the natural logarithm of the total number of alliances that the firm has entered prior to the focal alliance, since the variable is skewed to the right.

Sector. We have biotechnology firms that transcend three distinct sectors: therapeutics/vaccines, diagnostics and platform technologies. Of the three sectors, those firms involved in the therapeutic/vaccine market are markedly different in that they experience more expensive, longer and more uncertain development cycles. As such we define a dummy variable, Therapeutics/vaccines, if the firm is operating in that sector, 0 otherwise. Seventy-one percent of our firms are developing therapeutics or vaccines.

German firm. Given our disproportionate number of German respondents we create a dummy variable, German firm, which equals one if the firm is located in Germany, 0 otherwise. Forty-two percent of the firms in our sample are located in Germany. Even though the extant literature does not indicate country differences in terms of the preferences for or the allocation of control rights, being conservative we include this variable to account for potential differences.

\section{$4 \quad$ ANALYSIS AND RESUlts}

\subsection{Determinants of firm preferences for all rights}

Our first regressions are reported in Table 3 where we use an ordered logit model to examine how responses to eight control rights relate to a set of independent variables. Since our focus is on eight control rights each respondent has the opportunity to provide up to eight responses. Recall, each response is a Likert score corresponding to a specific control right. Our econometric approach, therefore, is to stack responses for each of our eight control rights in order to consider a single econometric model. This process creates a panel where the first firm (respondent) in the sample provides the first eight observations while the second firm provides observations 9 through 16, etc. Since each respondent (biotechnology firm) can appear in the data up to eight times, we use clustered standard errors to account for within firm 
correlations across the disturbances. Finally, in this first set of regressions we are assuming independence between each of the rights, an assumption we relax below in Section 4.2. (Table 3 approximately here)

Our results reveal that a firm's current capability stock is correlated with their preferences for control rights and they appear to vary across different types of capabilities. For example, our measure for $\mathrm{R} \& \mathrm{D}$ capability, Upstream capabilities, is positive and significant $(\mathrm{p}<0.05)$. This implies that firms that strongly cover upstream activities have a stronger preference for rights compared to firms that only partly cover or do not pursue upstream activities. While at first blush this seems logical for the biotechnology firm, these preference structures could cause conflict with a pharmaceutical partner. For example, Knowles and Higgins (2011) discuss the importance for pharmaceutical firms to maintain the right to litigate and control the IP strategy of a project.

Next, we consider the extent to which downstream capabilities are correlated with preferences for rights. Across all models in Table 3 Downstream capabilities is positively related to preferences for control rights, but it is not significant. However, our measure for whether a firm has plans to expand downstream, Downstream expansion, is a strong predictor $(\mathrm{p}<0.01)$ of preferences for rights. Firms that expand downstream and enter into alliances in order to learn about downstream capabilities strongly prefer control rights. Recall that our dependent variable is a stack of all rights. These two results seem to suggest that firms that have strong downstream capabilities do not have an overall preference for a broader set of rights (as we will see below, they instead have a preference for very specific rights). In contrast, we know from above that firms that have significant basic R\&D capability have a stronger preference for rights; this carries over into their preferences when they decide to downstream expand.

In addition to upstream and downstream capabilities, we also test whether a firm's alliance capabilities (Alliance capabilities) are correlated their preferences for rights. Indeed, across Models 3 and 4 (Table 3) we find that firms with greater alliance capabilities have a greater preference for rights $(\mathrm{p}<0.10)$. Presumably, firms with greater alliance capabilities also have a better ability to manage a joint project and 
deal with unforeseen situations. Alternatively, greater capabilities may be reflecting the size of a commitment to an alliance. As such, firms may be attempting to mitigate risk through rights.

Turning to the control variables, our measure which controls for the financial motivation of the biotechnology firm (research-intensive partner), Alliances to acquire capital, is negatively but not significantly related to preferences for rights. Our control for the stage of the underlying research of the firm, Early stage firm, is negative and significant $(\mathrm{p}<0.05)$. That is, earlier stage firms have a lower preference for rights compared to firms in later stages. It may be the case, as we demonstrate below, that preferences across all rights may be lower but instead they may be highly specific to a particular subset of rights. Interestingly, we find that Need access to IP, is positively and significantly $(\mathrm{p}<0.01)$ related to preferences for rights. It appears that the greater a biotechnology firm's interest is in gaining access to IP from the partner, the more rights they want to retain. At first glance this finding is surprising but we will see that once we split the rights into upstream and downstream bundles we gain a more complete explanation for this result.

In order to explore whether firms that already have strong research capabilities and who aim to further strengthen those capabilities through alliances strive for more rights we interact Upstream capabilities and Need access to IP. Applying this interaction term to Model 4 (Table 3) reveals that the coefficient is negative, but not significant. ${ }^{15}$ Firm age and Alliance experience are both unrelated to preferences for rights. As we will discuss below, this seems to suggest that preferences for rights are not developed over time as a firm conducts more deals, lending support to the notion that capabilities are driving preferences. Finally, since we had a large number of respondents from Germany we control for country differences, however, the coefficient on German firm was not significant in any specification.

\subsection{Preferences for bundles of rights}

\footnotetext{
15 The coefficient equaled -0.07 with a standard error 0.09 . For brevity, detailed results are not reported in Table 3; however, the results are available from the authors.
} 
While the dependent variable in Table 3 comprised all rights, in Table 4 we present results which are based on the bundles of rights that our factor analysis identified in Section 3.3.2. ${ }^{16}$ The five models in the left panel (Table 4a) use Upstream rights as a dependent variable while the right panel (Table 4b) uses Downstream rights as a dependent variable. Whereas we stacked all eight rights in the econometric model in Table 3, for the dependent variable in Table 4a (Upstream Rights) we stack the four rights identified by the factor analysis in Table 1 (Ownership of patents, Obligation to litigate patent infringement, Right to sub-license and Product reversion right upon termination). Similarly, in Table $4 \mathrm{~b}$ we stack the rights identified by the factor analysis in Table 1 (Management of clinical trials, Control of initial manufacturing process, Marketing rights to the product/technology) to form our dependent variable (Downstream Rights). As we did for the analyses in Table 3, we again employ an ordered logit model with clustered standard errors. (Table 4 approximately here)

We find that firms with strong upstream capabilities (Upstream capabilities, $\mathrm{p}<0.05$ ) tend to prefer upstream rights (Table 4a, Models 1-5) but not downstream rights (Table 4b, Models 1-5). Correspondingly, we find that firms with strong downstream capabilities (Downstream capabilities, $\mathrm{p}<0.10$ ) have greater preferences for downstream rights (Table 4b, Models 2-5) but not upstream rights (Table 4a, Models 2-5). The first result is consistent with theory, suggesting that smaller, research intensive (biotechnology) firms will specialize in the set of tasks for which it has a comparative advantage and licensing any developments for subsequent commercialization (Gans and Stern, 2003). The second result is consistent with Rothaermel and Deeds (2004) who show that often biotechnology firms will withdraw from their upstream activities in order to focus on downstream activities; preferences for rights appear to mirror this decision.

Further, firms planning to expand downstream (Downstream expansion) have a strong preference for downstream rights $(\mathrm{p}<0.01)$. This finding suggests a possible misfit between a firm's current set of capabilities and their preferences for rights. Such firms might want to expand downstream in order to increase firm value but by doing so they might also become potential competitors of the former partner

\footnotetext{
16 With this analysis we now relax the rigid assumption of independence between rights.
} 
(Rothaermel and Deeds, 2004). Moreover, their main motivation for alliances is to learn from their partner. Presumably these partnerships show a higher likelihood of failure as their partners might have differing priors on the long-term objective of the partnership. In addition, if the biotechnology firm retains these rights, although the pharmaceutical firm has to bear a lower investment to perform the associated tasks, the pharmaceutical partner's alliance specific investment to "fit the partnership" (Hart and Moore, 1990: 1123) might be lower compared to a situation in which these rights are allocated to the incumbent.

In our results above (Table 3) we identified a positive relationship between Alliance capabilities and preferences for rights. When we bundle rights together, our results suggest that firms with stronger Alliance capabilities have a higher preference for upstream related control rights $(\mathrm{p}<0.10)$. It appears the strong preference for all rights (Table 3) was being driven by the strong preference for upstream rights, specifically. Recall, Alliance capabilities is defined as the resources a firm commits to a particular alliance. Consistent with our prior explanation, a desire for upstream rights, given a larger commitment of assets might be reflective of a firms desire to maintain flexibility but it may also reflect their desire to mitigate risk. An additional reason might be that these upstream rights are enforceable in court (Kloyer, 2011; Kloyer and Scholderer, 2012). ${ }^{17}$

In terms of our control variables, we find a positive and significant effect of Need access to IP on downstream rights. Often firms have already made investments in downstream co-specialized complementary assets (Chan et al, 2007). In this case, firms may seek out other products in order to keep these assets fully deployed but will only do so if they have the appropriate rights in place. Additionally, our results suggest a negative and significant correlation between Early stage firm and downstream rights but not with upstream rights. In unreported regressions, we exclude the variable Upstream capabilities and Need access to IP but the coefficient on Early stage firm remained insignificant (Model 1 - Model 5, Table 4a). It appears that Age matters for downstream related rights in that older firms pursue more rights, but it does not appear to matter for upstream rights. As in our previous specification, Alliance experience has no im-

\footnotetext{
${ }^{17}$ We thank an anonymous referee for suggesting this point.
} 
pact on preferences. Therapeutic/vaccine firms tend to have a stronger preference for upstream over downstream rights, but the coefficient is significant in only one specification (Model 1, Table 4a). Again, in unreported regressions, we included a dummy variable for firms developing diagnostics; it was not significant nor did it impact the other variables in the model. Finally, we find neither direct country effects nor significant country differences when we interact our main independent variables with country dummies. This is consistent with Reuer and Arino (2007) who also did not find any cross-country effects in their analysis of ex post allocations of rights.

\subsection{Robustness}

\subsubsection{Liquidity constraints and preferences for rights}

To ensure the robustness of our results, we run a number of additional checks. The extant literature (e.g., Lerner et al, 2003) suggests that liquidity constraints influence the contractual structure and allocation of rights in alliances. We explore whether these liquidity constraints influence preferences for rights. We find that firms that were motivated to enter alliances to acquire capital (Alliances to acquire capital), and thus are presumably more cash constrained, do not appear to have a lower (or higher) preference for upstream or downstream rights. We interact the variables Alliances to acquire capital and Early stage firm in order to check whether there is any impact on these particularly cash constrained upstream focused firms; none was found (Model 5, Table 3, and Model 5 in Table 4a and Table 4b). While previous studies point out that liquidity constraints appear to cause loss of rights in the actual negotiation process, our findings show that these constraints do not appear to have any impact on preferences. In general, this is the pattern we would want to see since it suggests that preferences are flowing from capabilities and are not being distorted by other factors. It does suggest, however, an important role for the actual negotiation, a topic beyond the scope of this paper but which we discuss below.

\subsubsection{Alliance experience and the formation of preferences}


We limit our sample to those biotechnology firms that have engaged in at least one alliance. More accurately, our results can thus be viewed as conditional on a firm having entered at least one alliance. This was done, as we discussed above, so we could ensure that preferences for rights were contemplated by the firm within the context of an actual alliance. The question now becomes what role alliance experience plays in the formation of preferences, if any. In specifications presented in Tables 3 and 4, Alliance experience was not significantly related to a firm's preferences for all rights (Table 3) or specific bundles of rights (Table 4). While there does not appear to be any significant relationship between the number of alliances and preferences for rights, we next test the difference between those firms that engage in many alliances versus those that engage in few. Results are reported in Table 5.

The split between firms with and high and low alliance experience is based on the median number of alliances, i.e., firms with more than two alliances with pharmaceutical firms are categorized as "high alliance experienced". Correspondingly, firms with less than two alliances with pharmaceutical firms are categorized as "low alliance experienced." The only right that is significantly different is Management of Clinical Trials. In this case, biotechnology firms that enter more alliances have a lower preference for this right. This right is typically related to downstream activities and thus dominated by pharmaceutical firms. Besides this right it does not appear that a biotechnology firm's alliance experience influences their preference for control rights. Ruling out experience as a driver of preferences reinforces our findings that they are being formed based on firm capabilities. It remains a possibility, however, that there is a difference between zero and one alliance but that is beyond the scope of this paper. One would need more reliable data about firm preferences for those firms that have never entered an alliance. (Table 5 approximately here)

\subsubsection{Preferences or anticipated equilibrium outcome?}

A problem could arise with the interpretation of our results if respondents were not expressing firm preferences for rights but rather an anticipated equilibrium outcome. If our survey respondents were in fact expressing some type of anticipated outcome then we would expect to see strong correlation be- 
tween ex ante preferences for rights and actual ex post allocations. We do not have ex post allocation data for our respondents, but we can turn to other studies that have reported such allocations in the biopharmaceutical industry. While this analysis is ad hoc we can nevertheless begin to shed some light onto this question. In Table 6 we compare our average ex ante preferences for rights with actual ex post allocations from Higgins (2007). For our ex ante preferences we define a dummy equal to one when the firm considered a particular right to be "very important" or "extremely important". Comparing our ex ante preference for rights to actual ex post allocation reveals considerable differences thereby suggesting that the respondents were in fact providing preferences for rights versus some anticipated equilibrium outcome. (Table 6 approximately here)

\section{DISCUSSION}

Two strands of literature are particularly central to organizational strategy. One strand focuses on the theory of the firm (e.g., Williamson, 1985; 1993; Coase, 2006) and accentuates organizational efficiency, but has been criticized (Langlois, 1992; Kogut and Zander, 1992) for saying little about organizational heterogeneity (Foss and Klein, 2008). In contrast, the second strand, based on the capabilities perspective (e.g., Wernerfeldt, 1984; Barney, 1991; Teece et al., 1992), is a theory of organizational heterogeneity and sustainable performance differences, but lacks the ability to address organizational forms and governance arrangements that create capability differences (Foss, 1996a; 1996b) and is unclear on the mechanisms between capabilities and economic organization (Foss, 2005). As we discuss below, these two theories are not necessarily mutually exclusive.

Our study demonstrates that the capabilities perspective offers important insights that allow us to make extensions to the property rights framework. The GHM framework suggests that control rights should be allocated to the partner who can have the highest marginal impact on project success; our study supports this view. However, the literature lacks an adequate understanding about how firms differ in terms of "marginal impact". We hypothesize that one possible explanation for these differences lies in the heterogeneity of firm capabilities and indeed we find that this heterogeneity leads firms to prefer different 
bundles of control rights. By aligning preferences for rights and capabilities, firms with the knowledge or ability will be better able to direct specific activities (Demsetz, 1988) thereby contributing the marginal impact suggested by the GHM framework. In other words, rights follow the benefits of specialization in knowledge (Kogut and Zander, 1993).

In addition to providing a possible explanation on the origins of these marginal impacts, thereby linking the capabilities literature to the GHM framework, we further extend the property rights perspective by differentiating between current and future capabilities. In general, as Aghion and Tirole acknowledge (1994), the property rights literature offers a more static view of innovation management. By combining this framework with the capabilities perspective we provide insight into not only the rights a firm prefers based on their bundle of current capabilities but it also allows us to consider the development of firm capabilities in a more dynamic context. That is, we find that firms that have the intention to expand downstream begin to prefer downstream rights before they acquire those capabilities.

This preference formation prior to the acquisition of capabilities is consistent with both the GHM framework and also the closely related incentive systems literatures (Gibbons, 2005). The property rights literature proclaims ex ante incentive alignment; the surplus share of a partner will determine its investment incentive. Therefore, more rights assigned to a party "guarantees a bigger surplus share and insofar creates a stronger investment incentive" (Gibbons, 2005: 205). Indeed, we find that the partner willing to build up downstream capabilities asks for these decision rights. This alignment between preferences and future expansion capabilities is therefore efficient and akin to the incentive systems literature (Gibbons, 2005).

Moreover, if such an alignment between preferences and firm capabilities are subsequently reflected in the ex post allocation; then it may be possible to achieve a more ex ante efficient contract thereby reducing the need for re-negotiation (Lerner et al., 2003). For example, Grossman and Hart (1986) argue that because contracts are incomplete they cannot be efficiently allocated ex ante and because actions cannot be contractually fixed ex ante, re-negotiations are necessary and efficient. Our study, howev- 
er, suggests that by integrating aspects of the capabilities perspective a much better ex ante allocation is possible, which helps avoid unspecified ex post actions. We agree that while it is not possible to write a complete contract, having ex ante preferences (and subsequent ex post allocations) aligned with capabilities will ensure that the relevant partner will have the right (and obligation) to address possible contingencies thereby alleviating the need for re-negotiation.

Overall, the capabilities perspective takes a less opportunistic view of alliance activity. That is, many previous studies assume that firms strictly prefer more rights whereas we present a framework where firms should be more willing to trade rights to a partner if the partner has either superior capabilities or is better equipped to direct alliance activities (Demsetz, 1988). Our results suggest that if parties ask for rights not aligned with current capabilities then they should be willing to build up those capabilities; having the appropriate rights provides a strong incentive to do so. Furthermore, allocations to the more informed party also serve as a mechanism to reduce information distortions. This implies that the role of bargaining power may have been overemphasized by previous research. This less opportunistic view is consistent with Love (2005: 382) who argues that “...contractual issues do not everywhere and always hinge on opportunism a la Williamson, and that contracts can have functions beyond those merely of incentive alignment to prevent wrongdoing."

Besides avoiding opportunism and possible risk of holdup (Anand and Galetovic, 2000), possible functions of contracts (which are often neglected in the theory of the firm) include providing guidance about what to do in the event of uncertainty (Langlois, 1997) or to identify early on potential misunderstandings or "honest disagreements" (Alchian and Woodward, 1988). This view is also supported by the observations that contracts are even used, when opportunism is unlikely to be a serious economic threat. In this context, an integration of the capabilities perspective adds an intrinsic type of motivation to the extrinsic type so far emphasized in the theory of the firm in which actions of individuals are assumed to be directly related to an incentive-wise encouragement from an external force (e.g., Foss and Klein, 2008). This intrinsic type of motivation expressed in the voluntarily alignment of capabilities and contractual 
structure might be a source of superior alliance performance, which creates a competitive advantage and, ultimately, superior firm performance.

\section{CONCLUSION AND LIMITATIONS}

We motivated our paper by suggesting that preferences for control rights are important; however, little is known about them or how firms form their preferences. We believe we make several contributions to the literature. First, our unique survey data allow us to present empirical evidence on the existence of preferences for control rights and the extent of heterogeneity that exists between them. Additionally, by using factor analysis we are able to uncover the interdependence between rights and categorize them into bundles. This suggests that the assumption of equality and independence of rights are real caveats of previous studies (e.g., Lerner and Merges, 1998; Lerner et al., 2003; Higgins, 2007; Elfenbein and Lerner, 2009; Haeussler and Higgins, 2009), especially those focusing on specific rights (e.g., Lerner and Malmendier, 2010). In general, our findings should signal a cautioning tone for those scholars that seek to examine particular provisions of contracts in isolation. By documenting the interdependence between rights scholars intent on focusing on single rights may be better served by thinking instead about bundles of rights.

Second, we argue that firm capabilities, both current and future, drive a firm's preferences for control rights. This suggests that allocation follows the benefits of specialization in knowledge (Kogut and Zander 1993; Demsetz 1997) and that rights should flow to the partner with the specialized capabilities allowing them to set the general goal of the cooperative effort and monitor the degree to which the other partner accomplishes their task. Likewise, this view suggests that firms without a specific capability should be willing to trade a specific right or bundle of rights to their partner if that firm has the superior capability. This view corresponds with property rights theory and, as such, our findings support its notion that decision rights should be allocated to the party who can have the strongest marginal impact on outcome. 
We extend the property rights literature in two important ways. First, we add to the front end of the theory in that we offer one possible explanation for the source of a firm's "higher marginal impact". Second, we split the capabilities that explain the "impact on alliance outcome" (Shan et al., 1994; Rothaermel and Deeds, 2004) into current and future expansion capabilities. The formation of future expansion capabilities, in particular, is also consistent with the incentive systems literature (Gibbons, 2005); firms are incentivized to build up capabilities when they receive the associated control or decision rights. Insofar, we move beyond the static view of current capabilities by taking a firm's desire to expand downstream into account. Firms that indicated a plan to expand downstream also showed a preference for corresponding downstream rights. This suggests, in a broader context, that it is not just capabilities that drive preferences for rights but also the intention to build capabilities. It also suggests that these firms want to learn from their partners (Hamel, 1991; Khanna et al., 1998; Rothaermel and Deeds, 2004; Hsu and Wakeman, 2012). Notwithstanding this desire to acquire capabilities and learn, we cautioned that it is possible that capabilities end up being duplicated leading to an increase in costs. In this case, firms potentially face a dilemma: partners may have competitive, as well as collaborative aims vis-à-vis each other where they try to acquire one another's capabilities. This may well result in a "competition for competence" that ultimately destabilizes the relationship (Hamel, 1991).

Third, prior literature stresses the importance of alliance capabilities (Kale and Singh, 2007). We add to this literature by demonstrating that the strength of alliance capabilities positions a firm to efficiently decide about upstream related activities, which in turn, increase their preferences for upstream rights. This result complements Kale et al. (2002: 765) who find that “...one way of having alliance capability and greater alliance success was to create a dedicated alliance function." While most previous studies on alliance capabilities have focused on their impact on alliance success, we demonstrate that an important intermediate step to take is to consider their influence on contract structure. Coupled together these findings imply that superior alliance performance emanating from alliance capabilities is flowing from a firm's upstream capabilities and decisions. Hence, the value that a capabilities owner can create and ap- 
propriate depends not only on the use of the upstream capabilities but also on alliance capabilities, or transaction costs of trading and protecting the associated property rights.

No work is without limitations and ours is no exception. With our survey we gained more detailed knowledge about the biotechnology firm, their motivations and preferences but we lack information about their pharmaceutical partner. This prevents us from considering important issues such as relative bargaining position or relative complementarities between the firms (Adegbesan and Higgins, 2011). In a perfect setting we would want more complete information about the capabilities of all contractual parties. Moreover, in this project we focus on the determinants of preferences for rights. In future research we intend to match these preferences for rights with actual ex post allocations. Such an exercise will demonstrate the definitive role of bargaining power in this context.

Interestingly, we get a glimpse of what such a study may reveal. We know from Lerner et al. (2003) and Higgins (2007) that financial constraints affect the bargaining power of the research-intensive (biotechnology) firm. However, we demonstrate here that while cash constraints and the desire to access capital are significant motivations for firms entering alliances, this lack of capital does not affect a firm's preference for rights. By meshing our approach with this prior work the actual loss as a result of bargaining position (due to financial constraints) can be more fully understood.

One could further extend this type of analysis by linking it to alliance outcomes. What happens to the probability of a successful outcome if there is a mismatch between firm preferences and actual allocations? Moreover, such an analysis could shed light on the impact of opportunism. It may be the case that short term opportunism outweighs longer term gains; however, we tend to not think this is the case, especially in this research setting which has become so highly dependent upon external technology. Further research might explore subsequent deal structures for those firms that might choose to act opportunistically.

Considering a more dynamic perspective suggests that a firm's capability set is changing; is it thus possible to see corresponding changes in ex ante preferences and ex post allocations through time? If so, this implies managers are adapting to their changing capabilities over time; if not, this suggests inefficien- 
cy in contracting and a potential loss of value to the firm. As a corollary, understanding how quickly preferences change with shifts in underlying firm capabilities is also important. Does this organizational efficiency suggest anything about subsequent firm performance?

In conclusion, we believe that our study opens up many exciting vistas for future work, and we seek to stimulate further theoretical refinement and empirical investigation in this critical area of research. 


\section{References}

Adegbesan, T., Higgins, M., 2011. Intra-alliance performance, control rights and today's split of tomorrow's value. Strategic Management Journal 32(2), 187-211.

Aghion P, Tirole J., 1994. The management of innovation. Quarterly Journal of Economics 109: 11851209.

Alchian, A.A., Woodward, S., 1988. The firm is dead; long live the firm. A review of Oliver E.. Williamson's the economic institutions of capitalism. Journal of Economic Literature 26: 65-79.

Anand, B., Khanna, T., 2000. Do firms learn to create value? The case of alliances. Strategic Management Journal 21(3): 295-315.

Anand, B., Gelatovic, A., 2000. Weak property rights and holdup in R\&D. Journal of Economics and Management Stratetgy 9(4): 615-642.

Argyres, N., Mayer, K., 2007. Contract design as a firm capability: An integration of learning and transaction cost perspectives. Academy of Management Review 32(1): 1060-1077.

Armstrong, J.B., Overton, T.S., 1977. Estimating non-response bias in mail surveys. Journal of Marketing Research 14: 396-402.

Arora, A., Ceccagnoli, M., 2006. Patent protection, complementary assets, and firms' incentives for technology licensing. Management Science 52: 292-308.

Arora, A., Fosfuri, A., Gambardella, A., 2001. Markets for technology and their implications for corporate strategy. Industrial and Corporate Change 10(2): 419-451.

Barney J. B. 1991. Firm resources and sustained competitive advantage. Journal of Management 17: 99120.

Bresnahan, T., Gambardella, A., 1998. Licensing the market for technology. in E. Helpman (Ed.), General Purpose Technologies and Economic Growth. MIT Press: Cambridge, MA.

Casciaro, T., Piskorski, M.J., 2005. Power imbalance, mutual dependence, and constraint absorption: a closer look at resource dependency theory. Administrative Science Quarterly 50: 167-199.

Ceccagnoli, M., Graham, S.J., Higgins, M.J., Lee, J., 2010. Productivity and the role of complementary 
assets in firms' demand for technology innovations. Industrial and Corporate Change, forthcoming.

Chan, T., Nickerson, J., Owan, H., 2007. Strategic management of R\&D pipelines with cospecialized investments and technology markets. Management Science 53: 667-682.

Cheung, S., 1983. The contractual nature of the firm. Journal of Law and Economics 26: 1-21.

Ciccotello, C. S., Hornyak, M. J., 2000. Cooperation via contract: an analysis of research and development agreements. Journal of Corporate Finance 6: 1-24.

Clark, K., Fujimoto, T. 1990. The power of product integrity. Harvard Business Review 68(6): 107-118.

Coase, R.H., 1937. The Nature of the Firm. Economica 4: 386-405.

Coase, R., 2006. The conduct of economics: The example of Fisher Body and General Motors. Journal of Economics and Management Strategy 15(2): 255-278.

Cullen, W.C., Dibner, M.D. 1993. Strategic alliances in biotechnology: Imperatives for the 1990s. Biotechnology Review 1: 110-119.

Danneels, E. 2008. Organizational antecedents of second-order competences. Strategic Management Journal 29: 519-543.

Das T.K., Teng, B.S., 1998. Between trust and control: Developing confidence in partner cooperation in alliances. Academy of Management Review 23(3): 491-512.

Deeds, D.L., DeCarolis, D.M., Coombs, J.E., 1999. Dynamic capabilities and new product development in high technology ventures: An empirical analysis of new biotechnology firms. Journal of Business Venturing 15: 211-229.

Demsetz, H., 1988. The theory of the firm revisited. Journal of Law, Economics and Organization, 4: $141-161$.

Demsetz, H. 1997. The Economics of the Business Firm: Seven Critical Commentaries, Cambridge, Cambridge University Press.

Eisenhardt, K.M., Martin, J.A., 2000. Dynamic capabilities: What are they? Strategic Management Journal 21(10-11): 1105-1121.

Elfenbein, D., Lerner, J. 2003. Ownership and control rights in internet portal alliances, 1995-1999. 
Rand Journal of Economics 34: 356-369.

Emerson, R.M., 1962. Power-dependence relations. American Sociological Review 27(1), 31-44.

Foss, N.J., 2005. Strategy and Economic Organization in the Knowledge Economy. Oxford: Oxford University Press

Foss, N.J., Klein, P.G., 2008. The theory of the firm and its critics: A stocktaking and assessment. In: Brousseau, É. (Ed.), New Institutional Economics: A Guidebook. Cambridge University Press: Cambridge, p.425-442.

Foss, N. J., 1996A. Knowledge-based approaches to the theory of the firm: some critical comments, Organization Science 7, 470-476.

Foss, N.J., 1996B. More critical comments on knowledge-based theories of the firm. Organization Science 7, 519-523.

Gans, J., Hsu, D., Stern, S., 2002. When does start-up innovation spur the gale of creative destruction? Rand Journal of Economics 33: 571-586.

Gans, J., Stern, S., 2000. Incumbency and R\&D incentives: Licensing the gale of creative destruction. Journal of Economics and Management Strategy 9(4): 485-51.

Gans, J., Stern, S., 2003. The product market and the market for "ideas": commercialization strategies for technology entrepreneurs. Research Policy 32(2): 333-350.

Gawer, A., Henderson, R., 2007. Platform owner entry and innovation in complementary markets: Evidence from Intel. Journal of Economics and Strategy Management 16(1): 1-34.

Gibbons, R. 2005. Four formal(izable) theories of the firm? Journal of Economic Behavior and Organization 58: 200-245.

Giovannetti G.T., Morrison, S.W., 2000. Convergence: The Biotechnology Industry Report. Ernst \& Young: Palo Alto, CA

Grossman, S., Hart, O., 1986. The costs and benefits of ownership: A theory of vertical and lateral integration. Journal of Political Economy 94(4): 691-719

Haeussler, C., 2011. The determinants of commercialization strategy: Idiosyncrasies in British and 
German biotechnology. Entrepreneurship Theory and Practice 35(4): 653-681.

Haeussler, C., Patzelt, H., Zahra, S., 2012. Strategic alliances and product development in high technology new firms: The moderating effect of technological capabilities. Journal of Business Venturing 27, 217-233.

Hagedoorn, J., Hesen, G., 2009. Contractual complexity and the cognitive load of R\&D alliance contracts. Journal of Empirical Legal Studies 6: 818-847.

Hamel, G., 1991. Competition for competence and inter-partner learning within international strategic alliances. Strategic Management Journal 12: 83-103.

Hamel, G., Y. Doz and C. K. Prahalad (1989). Collaborate with your competitors-and win. Harvard Business Review 67(1): 133-139.

Hart, O., Moore, J., 1988. Incomplete contracts and renegotiation. Econometrica 56(4): 755-785.

Hart, O., 1995. Firms contracts and financial structure. Clarendon Press: Oxford, UK.

Hart O, Moore J., 1990. Property rights and the nature of the firm. Journal of Political Economy 98(6): 1119-1158.

Helfat, C., 1997. Know-how and asset complementarity and dynamic capability accumulation: the case of R\&D. Strategic Management Journal 18(5): 339-360.

Helfat, C., Finkelstein, W., Mitchell, W., Peteraf, M.A., Singh, H., Teece, D., Winter, S., 1997. Dynamic Capabilities: Understanding Strategic Change in Organizations. Blackwell, Oxford, UK.

Henderson, R., Cockburn, I., 1994. Measuring competence? Exploring firm effects in pharmaceutical research. Strategic Management Journal 15: 61-83.

Higgins, M.J., 2007. The allocation of control rights in pharmaceutical alliances. Journal of Corporate Finance 13: 58-75.

Higgins, M., Rodriguez, D., 2006. The outsourcing of R\&D through acquisitions in the pharmaceutical industry. Journal of Financial Economics 80: 351-383

Hoang, H., Rothaermel, F.T., 2005. The effect of general and partner-specific alliance experience on joint R\&D project performance. Academy of Management Journal 48(2): 332-345. 
Hsu, D., Wakeman, S., 2012. Cost and benefits of learning through alliances for entrepreneurial firms. European School of Management and Technology Working Paper No. 11-02(R2).

Inkpen, A.C., Crossan, M.M., 1995. Believing is seeing: Joint Ventures and organization learning. Journal of Management Studies 32(5): 595-617.

Kale, P., Dyer, J., Singh, H., 2002. Alliance capability, stock market response and long-term alliance success: The role of the alliance function. Strategic Management Journal 23: 747-770.

Khanna, T., 1996. Winner-take-all alliances. Harvard Business School working paper, No. 96-033.

Khanna, T., Gulati, R., Nohria, N., 1998. The dynamics of learning alliances: Competition, cooperation and relative scope. Strategic Management Journal 19: 193-210.

Klein, B., Crawford, R.G., Alchian, A., 1978. Vertical integration, appropriable rents, and the competitive contracting process. Journal of Law and Economics 21: 297-326.

Kloyer, M., Scholderer, J., 2012. Effective incomplete contracts and milestones in market-distant R\&D collaboration. Research Policy 41: 346-357.

Kloyer, M., 2011. Effective control rights in vertical R\&D collaboration. Managerial and Decision Economics 32: 457-468.

Knowles, S., Higgins, M.J., 2011. Vertical disintegration in the pharmaceutical industry and the role of IP. Intellectual Asset Management 45: 10-15.

Kogut, B., Zander, U., 1996. What do firms do? Coordination, identity and learning. Organization Science 7: $502-518$.

Kogut, B., Zander, U., 1992. Knowledge of the firm, combinative capabilities, and the replication of Technology. Organization Science 3: 383-397.

Koza M.P., Lewin, A.Y., 1998. The co-evolution of strategic alliances. Organization Science 9: 255-264. Krieger, D., Ruback, R.S., 2001. Merck and company: Evaluating a drug licensing opportunity. Case 9-201-023. Harvard Business School, Cambridge, MA.

Langlois, R., 1992. Transaction cost economics in real time. Industrial and Corporate Change 1: 99-127. 
Lerner, J., Malmendier, U., 2010. Contractibility and contract design in strategic alliances. American Economic Review 100(1): 214-246.

Lerner J., Merges, R.P., 1998. The control of technology alliances: An empirical analysis of the biotechnology industry. Journal of Industrial Economics 46(2): 125-156.

Lerner J., Shane H., Tsai, A., 2003. Do equity financing cycles matter? Evidence from biotechnology alliances. Journal of Financial Economics 67: 411-446

Levinthal, D.A., March, J.G., 1993. The myopia of learning. Strategic Management Journal 14: 95-112. Love, J.H., 2005. On the opportunism-independent theory of the firm. Cambridge Journal of Economics 29: $381-397$.

March, J. G., 1991. Exploration and exploitation in organizational learning. Organization Science 2(1): 71-87.

Mariti, P., Smiley, R.H., 1983. Co-operative agreements and the organization of industry. Journal of Industrial Economics 31(4): 437-451.

Mody, A., 1993. Learning through alliances. Journal of Economic Behavior Organization 20(2): 151-170. Mowery, D.C., Oxley, J.E., Silverman, B.S., 1996. Strategic alliances and interfirm knowledge transfer. Strategic Management Journal 17: 77-91

Nicholson, S., Danzon, P., McCullogh, J., 2005. Biotech-pharmaceutical alliances as a signal of asset and firm quality. Journal of Business 78(4): 1433-1464.

Parkhe, A., 1993. Strategic alliance structuring: a game theoretic and transaction cost examination of interfirm cooperation. Academy of Management Journal 36(4): 794-829.

PatVal-EU, 2005. The value of the European patents: Evidence from a survey of European inventors. Final report of the PatVal-EU Project, DG Science \& Technology, European Commission. Brussels. Peteraf, M.A., 1993. The cornerstones of competitive advantage: a resource-based view. Strategic Management Journal 14(3): 179-191.

Pisano, G., 1990. The R\&D boundaries of the firm: an empirical analysis. Administrative Science Quarterly 35: 153-176. 
Podsakoff, P.M., Organ, D.W., 1986. Self-reports in organizational research: Problems and prospects: Journal of Management 12(4): 531-544.

Powell, W., Brantley, P., 1992. Competitive cooperation in biotechnology: Learning through networks? In N. Nohria and R. Eccles (Eds.), Networks and Organizations: Structure, Form and Action. Harvard Business School Press, Boston, MA, pp. 365-394.

Reuer, J., Arino, A., 2007. Strategic alliance contracts: Dimensions and determinants of contractual complexity. Strategic Management Journal 28: 313-330.

Richardson, G.B., 1972. The organization of industry. Economic Journal 82: 883-896.

Rothaermel, F., Deeds, D., 2004. Exploration and exploitation alliances in biotechnology: A system of new product development. Strategic Management Journal 25: 201-221

Schilke, O., Goerzen, A., 2010. Alliance management capability: An investigation of the construct and its measurement. Journal of Management 36 (5): 1192-1219.

Shan, W., 1990. An empirical analysis of organizational strategies by entrepreneurial high-technology firms. Strategic Management Journal 11(2): 129-139.

Teece, D., 1986. Profiting from technological innovation. Research Policy 15(6): 285-305.

Teece, D., Pisano, G., Shuen, A. 1997. Dynamic capabilities and strategic management. Strategic Management Journal 18: 509-533.

Tirole, J., 1999. Incomplete contracts: Where do we stand? Econometrica 67: 741-781.

Wernerfelt, B., 1984. A resource-based theory of the firm. Strategic Management Journal 5(2): 171-180. Williamson, O., 1985. The Economic Institutions of Capitalism. New York: Free Press.

Zollo, M., Winter, S., 2002. Deliberate learning and the evolution of dynamic capabilities. Organization Science 13: 339-351. 
Table 1. Description of Control Rights and Factor Loadings

\begin{tabular}{|l|c|c|c|cc|}
\hline \multirow{2}{*}{ Control rights } & \multicolumn{3}{|c|}{ Descriptives } & \multicolumn{2}{c|}{$\begin{array}{c}\text { Factor analysis } \\
\text { (Factor loading) }\end{array}$} \\
\cline { 2 - 6 } & No.obs & Mean & Std.Dev. & $\begin{array}{c}\text { Upstream } \\
\text { Bundle }\end{array}$ & $\begin{array}{c}\text { Downstream } \\
\text { Bundle }\end{array}$ \\
\hline Ownership of patents & 157 & 3.90 & 1.01 & $\underline{0.78}$ & 0.16 \\
Obligation to litigate patent infringement & 152 & 3.33 & 1.01 & $\underline{0.67}$ & 0.11 \\
Right to sub-license & 156 & 3.32 & 1.12 & $\underline{0.78}$ & 0.06 \\
Product reversion rights upon termination & 148 & 3.63 & 1.21 & $\underline{0.63}$ & 0.32 \\
Right to publish & 156 & 2.74 & 1.07 & 0.35 & 0.27 \\
Management of clinical trials & 147 & 2.93 & 1.21 & 0.18 & $\underline{0.77}$ \\
Control of initial manufacturing process & 152 & 2.80 & 1.28 & 0.08 & $\underline{0.84}$ \\
Marketing rights to the product/technology & 157 & 3.35 & 1.18 & 0.25 & $\underline{0.75}$ \\
\hline
\end{tabular}

Note: Kaiser-Meyer-Olkin:0.78

Table 2. Summary Statistics and Correlations

\begin{tabular}{|c|c|c|c|c|c|c|c|c|c|c|c|c|c|c|c|}
\hline Variable & Obs & Mean & Std. Dev. & Min & $\operatorname{Max}$ & (1) & (2) & (3) & (4) & (5) & (6) & (7) & (8) & (9) & $(10)$ \\
\hline (1) Ups tream capabilities & 157 & 0.701 & & 0 & 1 & 1 & & & & & & & & & \\
\hline (2) Downstream capabilities & 157 & 0.197 & & 0 & 1 & -0.200 & 1 & & & & & & & & \\
\hline (3) Downstream expansion & 157 & -0.007 & 0.855 & -1.41 & 1.70 & -0.023 & -0.003 & 1 & & & & & & & \\
\hline (4) Alliance capabilities & 157 & 0.643 & & 0 & 1 & 0.181 & -0.265 & -0.054 & 1 & & & & & & \\
\hline (5) Alliances to acquire capital & 157 & 0.790 & & 0 & 1 & 0.004 & -0.215 & 0.129 & 0.171 & 1 & & & & & \\
\hline (6) Need access to IP & 157 & 0.299 & & 0 & 1 & -0.180 & -0.045 & -0.050 & 0.051 & -0.038 & 1 & & & & \\
\hline (7) Early stage firm & 157 & 0.197 & & 0 & 1 & 0.150 & -0.125 & -0.087 & 0.136 & -0.019 & -0.185 & 1 & & & \\
\hline (8) Age & 157 & 11.000 & 8.619 & 2 & 85 & 0.008 & 0.129 & -0.041 & -0.187 & -0.124 & 0.123 & -0.160 & 1 & & \\
\hline (9) Alliance experience & 157 & 10.242 & 22.102 & 0 & 235 & -0.150 & 0.138 & -0.120 & -0.067 & 0.003 & 0.038 & -0.102 & 0.066 & 1 & \\
\hline (10) Therapeutics & 157 & 0.707 & & 0 & 1 & 0.129 & -0.384 & 0.133 & 0.047 & 0.114 & 0.146 & -0.032 & 0.090 & -0.163 & 1 \\
\hline (11) Germany & 157 & 0.420 & & 0 & 1 & -0.176 & 0.096 & 0.026 & -0.039 & -0.067 & 0.007 & -0.001 & -0.051 & 0.086 & -0.161 \\
\hline
\end{tabular}


Table 3. Ordered Logit Results - All Control Rights

\begin{tabular}{|c|c|c|c|c|c|}
\hline \multirow[t]{2}{*}{ Variables } & \multirow[b]{2}{*}{ Model 1} & \multicolumn{3}{|c|}{ All Control rights } & \multirow[b]{2}{*}{ Model 5} \\
\hline & & Model 2 & Model 3 & Model 4 & \\
\hline \multirow[t]{2}{*}{ Upstream capabilities } & $0.426^{* *}$ & $0.444 * *$ & $0.462 * *$ & $0.415^{* *}$ & $0.418 * *$ \\
\hline & $(0.199)$ & $(0.193)$ & $(0.186)$ & $(0.185)$ & $(0.186)$ \\
\hline \multirow[t]{2}{*}{ Downstream capabilities } & & 0.194 & 0.157 & 0.216 & 0.206 \\
\hline & & $(0.203)$ & $(0.204)$ & $(0.200)$ & $(0.202)$ \\
\hline \multirow[t]{2}{*}{ Downstream expansion } & & & $0.385 * * *$ & $0.394 * * *$ & $0.393 * * *$ \\
\hline & & & $(0.114)$ & $(0.115)$ & $(0.114)$ \\
\hline \multirow[t]{2}{*}{ Alliance capabilities } & & & & $0.305^{*}$ & $0.307 *$ \\
\hline & & & & $(0.175)$ & $(0.174)$ \\
\hline \multirow{2}{*}{ Alliances to acquire capital $*$ Early stage firm } & & & & & -0.336 \\
\hline & & & & & $(0.487)$ \\
\hline \multirow[t]{2}{*}{ Alliances to acquire capital } & -0.0204 & 0.006 & -0.082 & -0.125 & -0.055 \\
\hline & $(0.179)$ & $(0.176)$ & $(0.189)$ & $(0.197)$ & $(0.216)$ \\
\hline \multirow[t]{2}{*}{ Need access to IP } & $0.414 * *$ & $0.421 * *$ & $0.514 * * *$ & $0.484 * * *$ & $0.498 * * *$ \\
\hline & $(0.185)$ & $(0.182)$ & $(0.183)$ & $(0.183)$ & $(0.187)$ \\
\hline \multirow[t]{2}{*}{ Early stage firm } & $-0.581 * *$ & $-0.564 * *$ & $-0.492 * *$ & $-0.529 * *$ & -0.267 \\
\hline & $(0.247)$ & $(0.248)$ & $(0.234)$ & $(0.232)$ & $(0.407)$ \\
\hline \multirow[t]{2}{*}{ Age } & 0.01 & 0.01 & 0.01 & 0.013 & 0.013 \\
\hline & -0.008 & -0.008 & -0.008 & -0.008 & -0.008 \\
\hline \multirow[t]{2}{*}{ Alliance experience (ln_alliances) } & -0.0679 & -0.0674 & -0.0514 & -0.0645 & -0.0635 \\
\hline & -0.091 & -0.091 & -0.087 & -0.085 & -0.085 \\
\hline \multirow[t]{2}{*}{ Therapeutic/vaccine } & 0.317 & 0.378 & 0.289 & 0.295 & 0.280 \\
\hline & $(0.213)$ & $(0.233)$ & $(0.225)$ & $(0.225)$ & $(0.228)$ \\
\hline \multirow[t]{2}{*}{ Germany } & -0.123 & -0.125 & -0.168 & -0.161 & -0.157 \\
\hline & $(0.172)$ & $(0.171)$ & $(0.166)$ & $(0.166)$ & $(0.166)$ \\
\hline Observations & 1,225 & 1,225 & 1,225 & 1,225 & 1,225 \\
\hline R squared & 0.052 & 0.052 & 0.062 & 0.063 & 0.064 \\
\hline Chi2 & 206.8 & 209.0 & 230.7 & 234.0 & 233.4 \\
\hline \multicolumn{6}{|l|}{ Robust standard errors in parentheses } \\
\hline$* * * \mathrm{p}<0.01, * * \mathrm{p}<0.05, * \mathrm{p}<0.1$ & & & & & \\
\hline
\end{tabular}


Table 4: Ordered Logit Results - Upstream and Downstream Rights

\begin{tabular}{|c|c|c|c|c|c|c|c|c|c|c|}
\hline \multirow[t]{2}{*}{ Variables } & \multicolumn{5}{|c|}{ Table 4a: Upstream Rights } & \multicolumn{5}{|c|}{ Table 4b Downstream Rights } \\
\hline & Model 1 & Model 2 & Model 3 & Model 4 & Model 5 & Model 1 & Model 2 & Model 3 & Model 4 & Model 5 \\
\hline \multirow[t]{2}{*}{ Upstream capabilities } & $0.526^{* *}$ & $0.511^{* *}$ & $0.528 * *$ & $0.466^{* *}$ & $0.476^{* *}$ & 0.335 & 0.381 & 0.395 & 0.379 & 0.380 \\
\hline & $(0.227)$ & $(0.223)$ & $(0.222)$ & $(0.219)$ & $(0.221)$ & $(0.283)$ & $(0.277)$ & $(0.269)$ & $(0.277)$ & $(0.277)$ \\
\hline \multirow[t]{2}{*}{ Downstream capabilities } & & -0.180 & -0.210 & -0.140 & -0.160 & & $0.509^{*}$ & $0.476^{*}$ & $0.495^{*}$ & $0.491^{*}$ \\
\hline & & $(0.248)$ & $(0.252)$ & $(0.248)$ & $(0.250)$ & & $(0.277)$ & $(0.274)$ & (0.274) & $(0.276)$ \\
\hline \multirow[t]{2}{*}{ Downstream expansion } & & & $0.264^{*}$ & $0.279^{* *}$ & $0.278^{* *}$ & & & $0.534 * * *$ & $0.536^{* * *}$ & $0.535^{* * *}$ \\
\hline & & & $(0.138)$ & $(0.139)$ & $(0.137)$ & & & $(0.160)$ & $(0.159)$ & $(0.159)$ \\
\hline \multirow[t]{2}{*}{ Alliance capabilities } & & & & $0.405^{*}$ & $0.416^{* *}$ & & & & 0.0999 & 0.100 \\
\hline & & & & $(0.216)$ & $(0.212)$ & & & & $(0.263)$ & $(0.262)$ \\
\hline \multirow[t]{2}{*}{ Alliances to acquire capital $*$ Early stage firm } & & & & & -0.747 & & & & & -0.102 \\
\hline & & & & & $(0.716)$ & & & & & $(0.676)$ \\
\hline \multirow[t]{2}{*}{ Alliances to acquire capital } & 0.0741 & 0.0477 & -0.000720 & -0.0536 & 0.104 & -0.116 & -0.0578 & -0.212 & -0.229 & -0.206 \\
\hline & $(0.258)$ & $(0.261)$ & $(0.270)$ & $(0.277)$ & $(0.291)$ & $(0.247)$ & $(0.244)$ & $(0.262)$ & $(0.274)$ & $(0.310)$ \\
\hline \multirow[t]{2}{*}{ Need access to IP } & 0.110 & 0.103 & 0.159 & 0.120 & 0.151 & $0.862 * * *$ & $0.880^{* * *}$ & $1.020 * * *$ & $1.009 * * *$ & $1.014 * * *$ \\
\hline & $(0.208)$ & $(0.209)$ & $(0.211)$ & $(0.213)$ & $(0.215)$ & $(0.275)$ & $(0.273)$ & $(0.281)$ & $(0.285)$ & $(0.290)$ \\
\hline \multirow[t]{2}{*}{ Early stage firm } & -0.407 & -0.423 & -0.385 & -0.419 & 0.158 & $-0.770 * *$ & $-0.713^{* *}$ & $-0.585^{* *}$ & $-0.600^{* *}$ & -0.520 \\
\hline & $(0.323)$ & $(0.318)$ & $(0.311)$ & $(0.311)$ & $(0.619)$ & $(0.305)$ & $(0.311)$ & $(0.296)$ & $(0.301)$ & $(0.589)$ \\
\hline \multirow[t]{2}{*}{ Age } & 0.00658 & 0.00751 & 0.00905 & 0.0128 & 0.0145 & $0.0232 * *$ & $0.0214 * *$ & $0.0211^{* *}$ & $0.0220 * *$ & $0.0223^{* *}$ \\
\hline & $(0.00935)$ & $(0.00953)$ & $(0.00969)$ & $(0.0103)$ & $(0.0104)$ & $(0.0104)$ & $(0.0104)$ & $(0.0104)$ & $(0.0107)$ & $(0.0108)$ \\
\hline \multirow[t]{2}{*}{ Alliance experience (ln_alliances) } & -0.00680 & -0.00762 & 0.00278 & -0.0105 & -0.00944 & -0.108 & -0.104 & -0.0789 & -0.0834 & -0.0833 \\
\hline & $(0.113)$ & $(0.113)$ & $(0.111)$ & $(0.108)$ & $(0.110)$ & $(0.111)$ & $(0.110)$ & $(0.105)$ & $(0.107)$ & $(0.107)$ \\
\hline \multirow[t]{2}{*}{ Therapeutic/vaccine } & $0.519^{*}$ & 0.463 & 0.385 & 0.397 & 0.371 & 0.192 & 0.359 & 0.282 & 0.281 & 0.275 \\
\hline & $(0.265)$ & $(0.291)$ & $(0.294)$ & $(0.296)$ & $(0.294)$ & $(0.296)$ & $(0.319)$ & $(0.300)$ & $(0.302)$ & $(0.309)$ \\
\hline \multirow[t]{2}{*}{ Germany } & -0.272 & -0.268 & -0.297 & -0.284 & -0.271 & 0.065 & 0.065 & -0.008 & -0.007 & -0.006 \\
\hline & $(0.221)$ & $(0.221)$ & $(0.219)$ & $(0.221)$ & $(0.222)$ & $(0.232)$ & $(0.231)$ & $(0.228)$ & $(0.228)$ & $(0.229)$ \\
\hline Question Fixed Effects & $\mathrm{Y}$ & $\mathrm{Y}$ & $\mathrm{Y}$ & $\mathrm{Y}$ & $\mathrm{Y}$ & $\mathrm{Y}$ & $\mathrm{Y}$ & $\mathrm{Y}$ & $\mathrm{Y}$ & $\mathrm{Y}$ \\
\hline Observations & 613 & 613 & 613 & 613 & 613 & 456 & 456 & 456 & 456 & 456 \\
\hline R squared & 0.0366 & 0.0370 & 0.0417 & 0.0451 & 0.0466 & 0.0483 & 0.0516 & 0.0691 & 0.0693 & 0.0693 \\
\hline Chi2 & 83.92 & 83.70 & 85.55 & 85.25 & 82.91 & 54.84 & 56.22 & 62.43 & 63.64 & 63.82 \\
\hline
\end{tabular}

Note: Robust standard errors in parentheses. $* * * \mathrm{p}<0.01, * * \mathrm{p}<0.05, * \mathrm{p}<0.1$ 
Table 5: Summary Statistics for Control Rights separated for High and Low Alliance Experienced Firms

\begin{tabular}{|l|r|r|r|r|r|r|c|}
\hline & \multicolumn{3}{|c|}{$\begin{array}{l}\text { High alliance experienced } \\
\text { Control rights }\end{array}$} & \multicolumn{2}{|c|}{ Low alliance experienced } & Diff.mean \\
& No.obs & Mean & Std.Dev. & No.obs & Mean & $\begin{array}{l}\text { Std.De } \\
\text { v. }\end{array}$ & p-value \\
\hline Ownership of patents & 55 & 3.93 & 1.07 & 91 & 3.90 & 0.96 & 0.73 \\
\hline Obligation to litigate patent infringement & 54 & 3.37 & 1.09 & 87 & 3.38 & 0.94 & 0.90 \\
\hline Right to sub-license & 55 & 3.36 & 1.24 & 90 & 3.33 & 1.03 & 0.64 \\
\hline Product reversion right upon termination & 53 & 3.74 & 1.32 & 84 & 3.62 & 1.10 & 0.33 \\
\hline Right to publish & 55 & 2.69 & 1.10 & 90 & 2.79 & 1.08 & 0.58 \\
\hline Management of clinical trials & 49 & 2.65 & 1.13 & 87 & 3.08 & 1.23 & 0.04 \\
\hline Control of initial manufacturing process & 51 & 2.67 & 1.34 & 90 & 2.91 & 1.24 & 0.26 \\
\hline Marketing rights to the product/technology & 53 & 3.25 & 1.31 & 93 & 3.42 & 1.09 & 0.54 \\
\hline
\end{tabular}

Note: The split between high and low alliance experienced firms are based on the median of number of alliances, i.e., firms with more than two alliances with pharmaceutical firms are categorized as high alliance experienced. Correspondingly, firms with less than 2 alliances with pharmaceutical firms fell in the low alliance experience category.

Table 6:Ex Ante Preference for Control Rights versus Ex Post Allocation

\begin{tabular}{|l|c|c|c|}
\hline & Ex ante preferences & $\begin{array}{l}\text { Ex post allocation } \\
\text { (Higgins, 2007) }\end{array}$ & Difference \\
\hline Control rights & & & $18 \%$ \\
\hline Ownership of patents & $64 \%$ & $82 \%$ & $-1 \%$ \\
\hline Obligation to litigate patent infringement & $43 \%$ & $42 \%$ & $-18 \%$ \\
\hline Right to sub-license & $47 \%$ & $29 \%$ & $-43 \%$ \\
\hline Product reversion rights upon termination & $61 \%$ & $18 \%$ & $2 \%$ \\
\hline Right to publish & $26 \%$ & $28 \%$ & $-15 \%$ \\
\hline Management of clinical trials & $35 \%$ & $20 \%$ & $0 \%$ \\
\hline Control of initial manufacturing process & $33 \%$ & $33 \%$ & $29 \%$ \\
\hline Marketing rights to the product/technology & $49 \%$ & $78 \%$ & \\
\hline
\end{tabular}

Note: The ex post actual allocation is based on the dataset used in Higgins (2007). The dataset uses information on 165 alliance contracts from Deloitte Recap between biotechnology and pharmaceutical firms. 